\title{
Key points of planning and design of Urban Ecological Wetland Park
}

\author{
(1 Southeast University Xian College Jiangsu Nanjing 2100882 Hefei city planning and Design Institute Anhui Hefei
} 230000)

In order to better protect the natural environment on the implementation of the full construction of the Wetland Park, which not only can well protect the city surrounding the wetland resources, but also can provide a good place for leisure and entertainment for people in the crowded city.

1. City Wetland Park Planning and design under the concept of Ecological Planning

1.1 The principle of sustainability

Due to excessive exploitation and utilization of human caused a mass extinction of wetland resources, and construction of the wetland park wetland resources on the periphery of the city can effectively protect and use ${ }^{[1]}$. is through the human disturbance way protection of wetland resources, so that its demise speed continues to slow, also contributed to the effective restoration of the original ecological environment, but can also be developed by [11]. and the moderate

\subsection{Suitability principle}

The construction of the wetland park is the natural ecosystem and the human intervention was an effective combination of processing, premise park function is a natural ecological environment does not affect wetland resources, and then make the specific combination of the actual situation of the scientific and reasonable division of the ${ }^{[2]}$.

2. Planning and design of City Ecological Wetland Park

\subsection{Landscape planning and design}

Different city wetland park vegetation based site environment is different, so the design of ecological landscape, should expand the overall vegetation landscape planning for the park, the overall planning to promote the overall development of ${ }^{[3]}$. park wetland landscape in different types of landscape vegetation coverage, key species, endemic species, with its clear partition [10]. first, hierarchical control, ecological core wetland. In order to maintain the original landscape features, to maintain native populations and fauna. Second, restoration of degraded wetlands area. In order to restore the wetland ecological restoration effect, in accordance with the original wetland vegetation

\begin{abstract}
: wetland is one of the three ecological systems, is sensitive to outside interference, the development of the city has many wetland resources are destroyed, a way of the construction of city wetland park is the protection and use of natural or artificial wetland resources, wetland ecological system optimization of the original building. At the same time to meet the leisure and recreation, science education the landscape space, reasonable use of the premise of protecting the ecological environment of wetland
\end{abstract}

Key words:Wetland Park; ecological planning; design points

Published on 30th Sept,2017 
landscape, play the ecological function of Wetland Third. The outdoor recreation area is dominated by native plants, forming the landscape effects of crops and landscape forest as the main characteristics. ${ }^{[4]}$.

\subsection{Drainage system carding}

Water is a very important part in wetland ecosystem, the design and construction of City Wetland Park Wetland Park is the key of [5]. respect the nature of the surface, according to the site situation, according to the water flow design, enrich the space form of wetland. The design should also pay attention to the use of dredging ditches ponds and ditches, the connection pool water system "'" up on farmland wetland areas occupied in the upstream of the water system through the purification of plant, slow flow etc. to ensure the water quality ${ }^{[6]}$. for wet in the water system, planning and design should be based on the terrain and water, and is connected with the water system of the whole, and form a dynamic water circulation, help to improve The quality of the water, creating a rich ecological landscape of wetland ${ }^{[7]}$.

\subsection{Shoreline protection}

The shoreline is aquatic environment and terrestrial environment at the junction of the coastline will generally change periodically, so the processing of revetment is particularly important. On the basis of revetment materials can be divided into hard, semi hard, gentle and natural ${ }^{[8]}$. can design the following 5 types of forms. The gentle slope revetment type: good hydrophilicity that applies to a larger space for the shore, can be achieved through the formation of cultivated land; the stakes: with stakes or piece of stone, can resist water erosion, both natural vegetation and landscape effect; and the steps with different level of high adaptability, both ecological and landscape value; the boulders were: convenient, ecological and landscape The concept of good effect; the platform type: suitable for the change of water level, flow concentrated area, provide hydrophilic space for visitors to ${ }^{[9]}$.

In a word, as the city continues to accelerate the process of the construction of city wetland park can be protected very well on the periphery of the city wetland resources, and also can take some reform measures so that it has more abundant function. So the protection and construction of city wetland park on the whole ecological system has a very important significance.

\section{Reference}

[1] Sun Guiling. Talking about the planning and design of plant landscape in Urban Wetland Park [J]. agricultural science and technology and information, 2016, (32): $118+121$.

[2]. Elastic sponge city and the city construction and development [J]. Shanxi architecture, 2017,43 (05): 21-22.
[3] Huang Beili, Peng Wenhui, Wu Lei. Planning and design of East Taihu eco Wetland Park [J]. Jiangsu forestry science and technology, 2015,42 (06): 35-39.

[4] Shi Yang. Ecological planning and landscape design of Urban Wetland Park [J]. modern horticulture, 2016, (06): 93.

[5] Cao Chuan. Chongqing Wetland Park ecological planning and design of $[\mathrm{J}]$. agricultural services, 2016,33 (06): 239+206.

[6] Li Dan. Study on the planning and design of Changzhi Urban Wetland Park [D]. Anhui Agriculture University, 2015.

[7] Zhao Chang. Study on ecological protection planning of wetland parks in arid areas of China [D]. Chinese Academy of forestry, 2016.

[8] et al. River ecological landscape type city wetland park planning and design of [D]. Yanshan University, 2015.

[9] Zhang Wei. Ecological city wetland park planning research based on [D]. system of Beijing Forestry University, 2016.

[10] Yin Luqin. Under the concept of ecological planning of city wetland park planning of [D]. Beijing Forestry University, 2016.

[11] Ma Li Ting. Xi'an Lintong Wetland Park Zixia lake landscape planning and design of [D]. Northwest Agriculture and Forestry University, 2016. 